\title{
Changes in Glycogen Content of Neutrophils in Eel, Anguilla japonica by Bacterial Infection
}

\author{
Yoshiaki Nagamura* and Hisatsugu WaKabayashi \\ Department of Fisheries, Faculty of Agriculture, University of Tokyo, \\ Yayoi 1-1-1, Bunkyo-ku, Tokyo 113, Japan
}

\begin{abstract}
Glycogen content of neutrophils in the eel which were injected with some extraneous materials such as formalin-killed cells, $2 \%$ solution of casein and physiological saline were determined and their locomotion and phagocytosis were also examined. The eel injected with bacteria had the highest content of neutrophil glycogen, ranged from $74.6 \mu \mathrm{g}$ to $105.9 \mu \mathrm{g}$ per $10^{7}$ neutrophils. The values in those injected with $2 \%$ solution of casein and physiological saline were $60.1-66.9 \mu \mathrm{g}$ and about $45 \mu \mathrm{g}$, respectively. In the locomotion of the nuetrophils, the neutrophils from the eel injected with $2 \%$ solution of casein migrated best, and those from the eel injected with bacteria did in the next place. The bacterial phagocytosis of the neutrophils was examined in vitro in the whole blood. Glycogen-rich neutrophils showed the most remarkable phagocytosis, though the locomotion was not promoted.
\end{abstract}

\section{Introduction}

Neutrophils are believed to play an important role in defence against bacterial infections. In mammals neutrophils are a major phagocytic cells and appear rapidly at an inflamatory site. In addition it is known that neutrophils in mammal include a large amount of glycogen in their cytoplasm and their glycogen are the energy source for motility (KAKINUMA, 1976; WAGNER, 1947).

We descrived that the neutrophils in the peripheral blood of the eel injected with bacteria showed changes in PAS reaction and these PAS positive substances in the neutrophils were identified as glycogen by salivery digestion test (Nagamura and WaKabayashi, 1983).

In the present study, we investigated the changes in glycogen content in the neutrophils of the eel injected with various extraneous materials like bacteria, and examined how the glycogen is used as a source of energy by examining the locomotion and phagocytosis of the neutrophils.

* Present address: Medical Dept. Research Laboratories Ueno Fine Chemical Industries, Ltd., 1-127, Higashiarioka, Itami-shi, Hyogo, Japan.

\section{Materials and Methods}

\section{Experimental Fish}

Eel (Anguilla japonica, $150-250 \mathrm{~g}$ of body weight) cultured in the Fisheries Laboratory of Tokyo University was used.

\section{Extraneous Materials}

The extraneous materials used were formalinkilled cells of Vibrio anguillarum and of Edwardsiella tarda, and 2\% solution of casein as well as physiological saline as a control.

\section{Blood Samples}

Blood samples were taken from the eel which were injected with formalin-killed cells of bacteria, $2 \%$ solution of casein and physiological saline before $12 \mathrm{hrs}$ or $24 \mathrm{hrs}$. Most of the whole blood cells were used for neutrophil isolation and the rest were prepared for the blood smears, which were stained with May-Grunwald Giemsa (MGG) and Periodicacid Shiff reaction (PAS).

\section{Isolation of the Neutrophils}

Neutrophils were separated from the peripheral blood by using Ficoll-Metrizoate solution (Fig. 1). One $\mathrm{m} l$ of undiluted blood were carefully loaded onto Ficoll-Metrizoate solution as the separation medium and the tube was centrifuged for $30 \mathrm{~min}$ at 

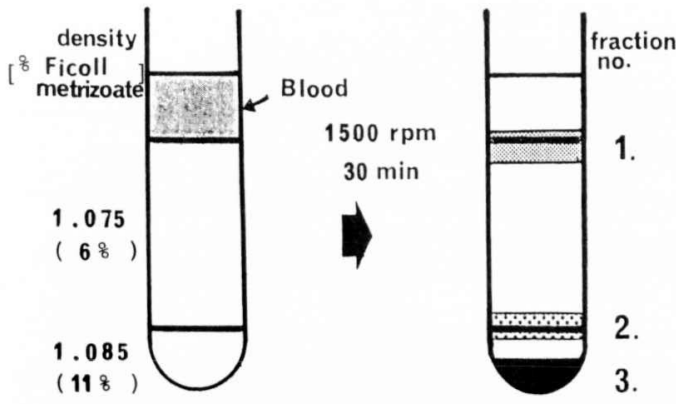

Fig. 1. Schematic representation of the discontinuous density Ficoll-metrizoate used for blood cell separation

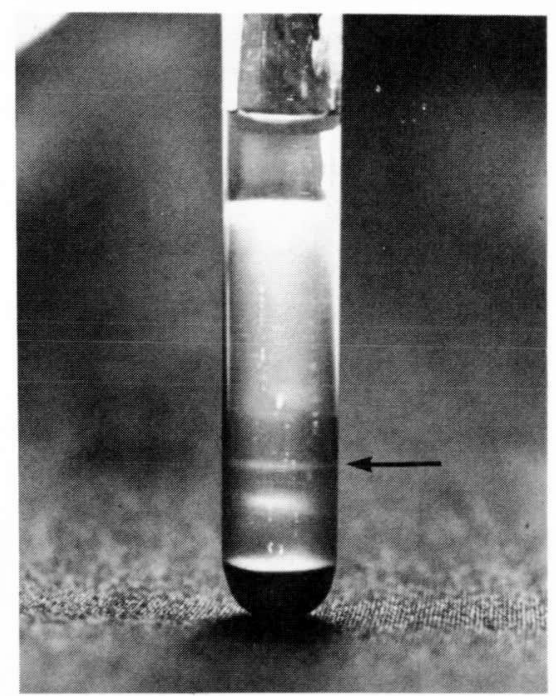

Fig. 2. Neutrophils separated by using a Ficollmetrizoate solution.

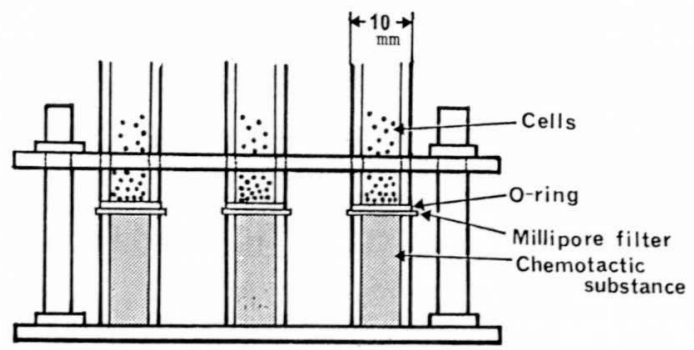

Fig. 3. Membrane filter apparatus.

\section{$1500 \mathrm{rpm}$.}

The whole blood cells were divided into three layers by centrifugation (Fig. 2). Fraction 1 contained thrombocytes and lymphocytes, Fraction 2 mainly neutrophils and Fraction 3 erythrocytes. The neutrophils in Fraction 2 were collected with pasteur pipette and their cells were washed three times with KRP.

\section{Glycogen Content of Neutrophils}

Glycogen content of neutrophils were determined by Montogomery's method.

\section{Locomotion of the Neutrophils}

Locomotion of the neutrophils were determined in vitro by a modification Boyden chamber method. Figure 3 showed the scheme of millipore filter apparatus to examine the locomotion of neutrophils. The upper chamber was filled with neutrophil suspension and the lower chamber was filled with the activated serum as a chemotactic substance. After preparation, this apparatus was incubated at $26{ }^{\circ} \mathrm{C}$ for $1 \mathrm{hr}$.

After incubation, the millipore filter was removed from the apparatus and then stained with hematoxylin. The migration distance of 100 neutrophils was measured under a microscopy.

\section{Phagocytosis of the Neutrophils}

The bacterial phagocytosis of neutrophils were examined in vitro using the whole blood cells. The whole blood cells were incubated with the bacterial suspension of E. tarda and shaked at $26 \mathrm{C}$ gently. After incubation, the blood smears were prepared at regular intervals and then stained with MGG and PAS.

The bacteria phagocytized by neutrophils were carefully observed microscopically.

\section{Results}

\section{Glycogen Content of Neutrophils}

The result of the determination of glycogen content of neutrophils are shown in Table 1. As shown in this table, the glycogen content of neutrophils was highest in the eel injected with bacteria, and it ranged from $74.6 \mu \mathrm{g}$ to $105.9 \mu \mathrm{g}$ per $10^{7}$ neutrophils. In the eel injected with $2 \%$ solution of casein, it ranged from $60.1 \mu \mathrm{g}$ to $66.9 \mu \mathrm{g}$. Neutrophils of the control fish injected with physiological saline had the lowest glycogen content of about $45 \mu \mathrm{g}$.

\section{Losomotion of the Neutrophils}

The migration distance of neutrophils in the eel 
Table 1. Glycogen content of neutrophils of eel injected with various irritants

\begin{tabular}{|c|c|c|c|c|c|c|}
\hline \multirow{2}{*}{ Irritant } & \multicolumn{5}{|c|}{ Mean percentage positivity } & \multirow{2}{*}{$\begin{array}{c}\text { Glycogen content } \\
\left(\mu \mathrm{g} / 10^{7} \text { cells }\right) \\
\text { Phenol- }-\mathrm{H}_{2} \mathrm{SO}_{4}\end{array}$} \\
\hline & I & II & III & IV & $\mathrm{V}$ & \\
\hline \multirow[t]{2}{*}{ Physiological saline } & 0 & 87.5 & 10.0 & 2.5 & 0 & 44.6 \\
\hline & 0.5 & 66.5 & 30.5 & 1.5 & 1.0 & 47.4 \\
\hline \multirow[t]{3}{*}{$2 \%$ Casein $^{* 1}$} & 2.0 & 61.5 & 35.5 & 1.0 & 0 & 60.1 \\
\hline & 0 & 60.0 & 39.0 & 1.0 & 0 & 66.8 \\
\hline & 0.5 & 24.5 & 69.5 & 5.5 & 0 & 66.9 \\
\hline \multirow[t]{4}{*}{$V$. anguillarum ${ }^{* 2}$} & 0 & 25.0 & 58.5 & 16.0 & 0.5 & 74.6 \\
\hline & 1.5 & 18.5 & 37.5 & 37.5 & 5.0 & 98.0 \\
\hline & 0 & 9.0 & 35.5 & 52.0 & 3.5 & 88.3 \\
\hline & 0 & 16.5 & 22.5 & 60.5 & 1.5 & 78.4 \\
\hline \multirow[t]{4}{*}{ E. $\operatorname{tarda} a^{* 2}$} & 0 & 26.0 & 47.5 & 26.5 & 0 & 77.5 \\
\hline & 1.0 & 19.5 & 33.0 & 46.5 & 0 & 84.6 \\
\hline & 0.5 & 6.0 & 22.5 & 67.5 & 3.5 & 103.3 \\
\hline & 0 & 2.5 & 26.0 & 66.0 & 5.5 & 105.9 \\
\hline
\end{tabular}

*1 These fish were injected intraperitoneally with $0.1 \mathrm{~m} l$ of $2 \%$ solution of casein $12 \mathrm{hrs}$ before bleeding.

*2 These fish were injected intraperitoneally with $1 \mathrm{mg}$ of formalin-killed cells of $V$. anguillarum and of $E$. tarda respectively $12 \mathrm{hrs}$ before bleeding.

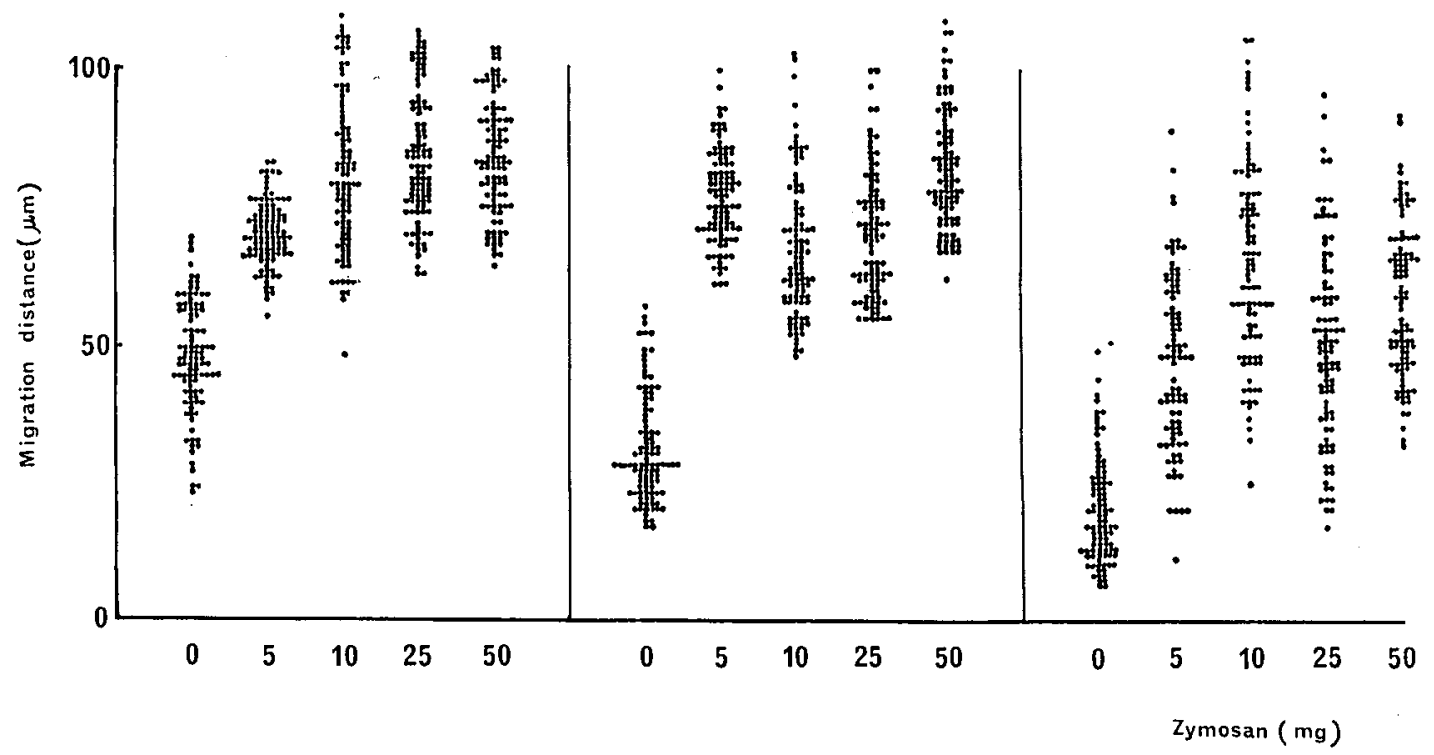

Fig. 4. Migration of neutrophils toward zymosan-activated serum. The neutrophils were obtained from eel which was injected with $2 \%$ solution of casein.

injected with formalin-killed bacteria, $2 \%$ solution of casein and physiological saline showed Fig. 4, Fig. 5 and Fig. 6, respectively. The neutrophils in the eel injected with $2 \%$ solution of casein showed a marked migration. In the fish injected with formalin-killed bacteria, the neutrophils migrated considerably. In the control fish injected with phys- iological saline, in comparison with neutrophils in the eel injected with $2 \%$ solution of casein or formalin-killed bacteria, the migration distance of the neutrophils varied widely.

\section{Phagocytosis of the Neutrophils}

The bacterial phagocytosis were examined in 


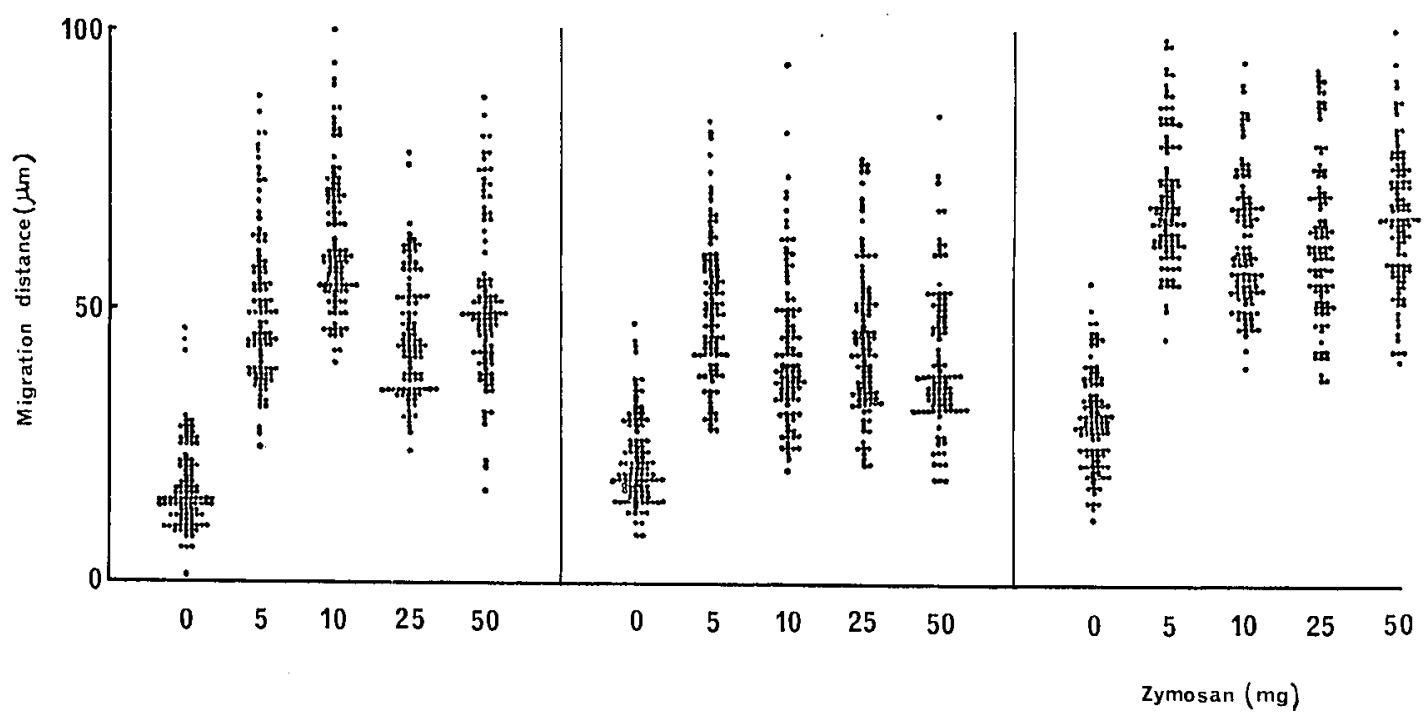

Fig. 5. Migration of neutrophils toward zymosan-activated serum. The neutrophils were obtained from eel which was injected with formalin-killed cells of E. tarda.

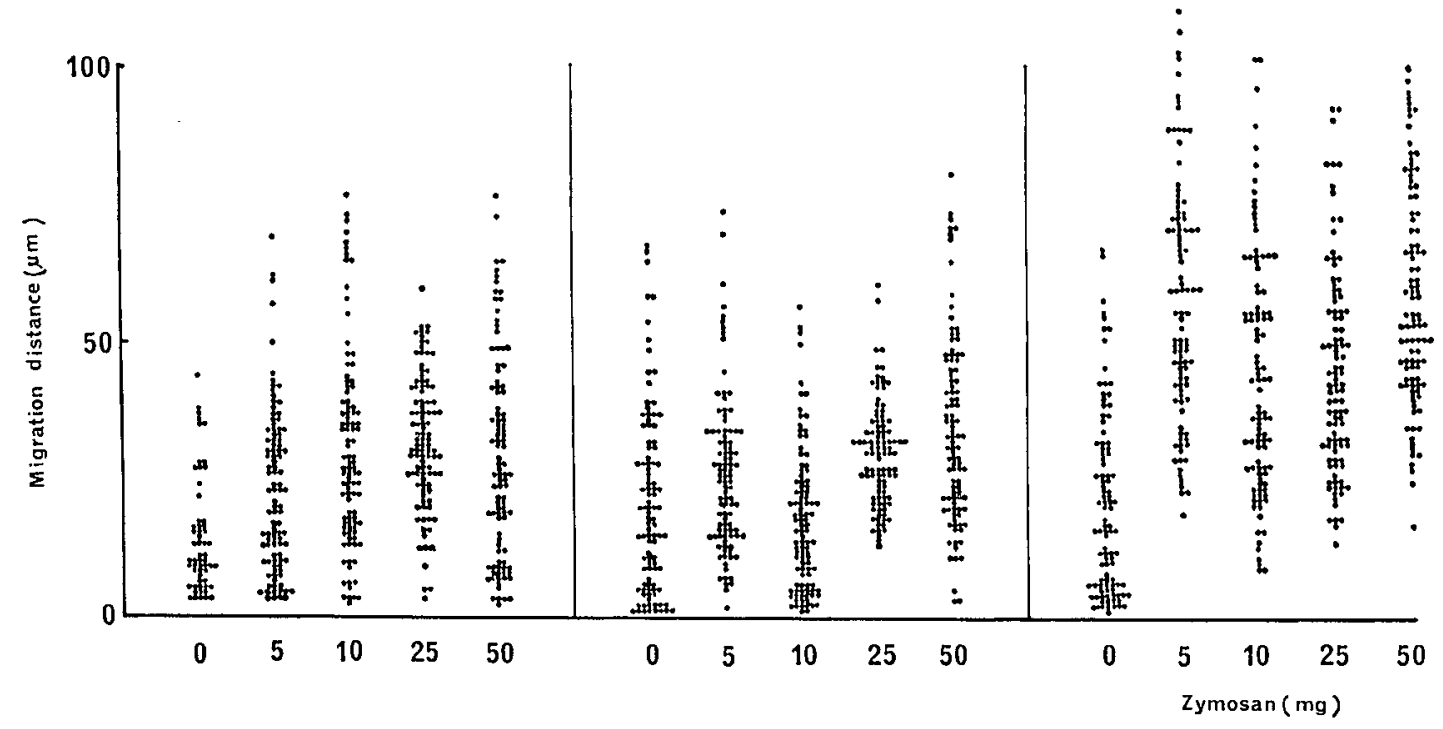

Fig. 6. Migration of neutrophils toward zymosan-activated serum. The neutrophils were obtained from eel which was injected with physiological saline.

vitro using the whole blood cells in the eel injected with formalin-killed cells of $E$. coli, with $2 \%$ solution of casein and with physiological saline. As shown in Table 2, after incubation for $30 \mathrm{~min}$, the neutrophils in the eel injected with the formalinkilled cells of $E$. coli showed a marked phagocytosis and their phagocytic rate were $40 \%$ and $56 \%$.
Whereas, the phagocytic rate of the neutrophils in the eel injected with physiological saline were $16 \%$ and $17 \%$. In the case of $2 \%$ solution of casein, it was the lowest.

The phagocytosis of the neutrophils against bacteria are shown in Fig. 7. The neutrophil phagocytized bacteria actively $30 \mathrm{~min}$ after incubation 


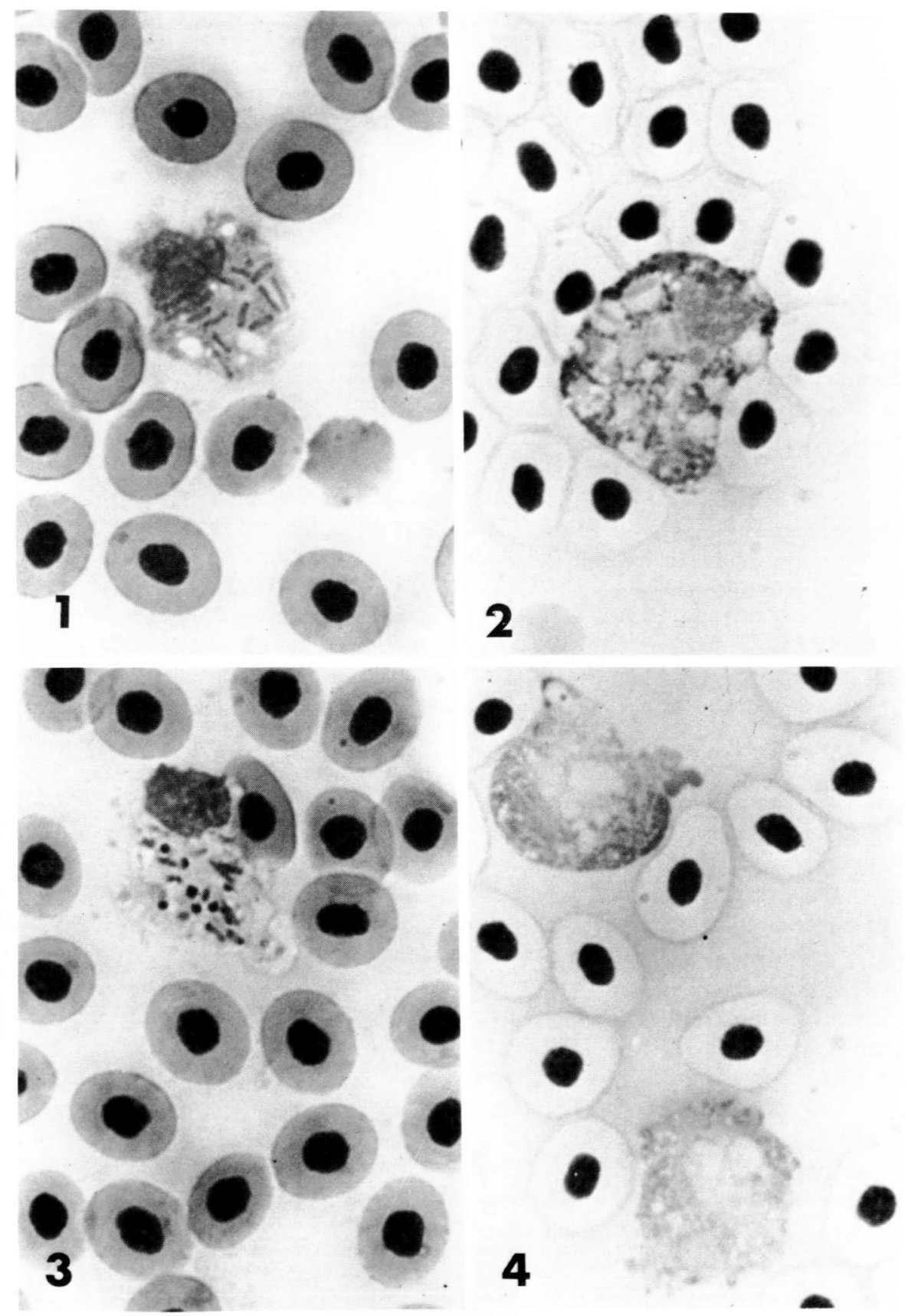

Fig. 7. Phagocytosis of the neutrophil. 1: After incubation for $30 \mathrm{~min}$, MGG stain. 2: After incubation for $30 \mathrm{~min}$, PAS reaction. 3: After incubation for $12 \mathrm{hr}$, MGG stain. 4: After incubation for $12 \mathrm{hr}$, PAS reaction. 
Table 2. Phagocytic activity of leukocytes from eel against E. tarda at $26^{\circ} \mathrm{C}$

\begin{tabular}{|c|c|c|c|c|}
\hline \multirow[b]{2}{*}{ Irritant } & \multicolumn{2}{|c|}{$30 \mathrm{~min}$} & \multicolumn{2}{|c|}{$4 \mathrm{hrs}$} \\
\hline & $\begin{array}{c}\text { Phagocytic rate } \\
(\%)\end{array}$ & Phagocytic index & $\begin{array}{c}\text { Phagocytic rate } \\
(\%)\end{array}$ & Phagocytic index \\
\hline \multirow[t]{2}{*}{ Physiological saline } & 17 & 0.43 & 97 & 9.47 \\
\hline & 16 & 1.09 & 96 & 5.37 \\
\hline \multirow[t]{2}{*}{$2 \%$ Casein $* 1$} & 8 & 0.09 & 100 & 9.46 \\
\hline & 1 & 0.01 & 99 & 9.60 \\
\hline \multirow[t]{2}{*}{ E. $\operatorname{coli}^{* 2}$} & 40 & 1.32 & 89 & 4.95 \\
\hline & 56 & 2.40 & 94 & 6.70 \\
\hline
\end{tabular}

*1 These fish were injected intraperitoneally with $0.1 \mathrm{~m} /$ of $2 \%$ solution of caseine $12 \mathrm{hrs}$ before bleeding.

*2 These fish were injected intraperitoneally with $1 \mathrm{mg}$ of formalin-killed cells of $E$. coli $12 \mathrm{hrs}$ before bleeding.

(Fig. 7-1) and the cytoplasm of their neutrophils were stained well with PAS (Fig. 7-2). After $12 \mathrm{hr}$ incubation, their neutrophils had vacuoles, where the phagocytized bacteria were observed and they became swollen, the PAS reaction of neutrophils phagocytizing bacteria became less prominent gradually (Fig. 7-3, 4).

\section{Discussion}

It is known that neutrophils in mammals contain a large amount of glycogen in their cytoplasm (KAKINUMA, 1976; WAGNER, 1947).

W AGNER (1947) reported that glycogen content of the white blood cells was $4.23 \mu \mathrm{g}$ per $10^{6}$ cells. In the control fish of eel, Glycogen content of neutrophils was about $45 \mu \mathrm{g}$ per $10^{7}$ cells, its value did not show clear defference in comparison with those of mammals. However, it is an interesting fact that the neutrophils in the eel injected with the bacterial cells have considerably larger amount of glycogen in cytoplasm than those in the eel injected with $2 \%$ solution of casein or physiological saline.

In locomotion of the neutrophils, the neutrophils in the eel injected with $2 \%$ solution of casein tend to migrate best and in the next place those of the eel injected with bacteria, followed by the control. In spite of the neutrophils in the eel injected with bacteria had a large amount of glycogen, they migrated less actively than those from the eel in- jected with $2 \%$ solution of casein. Therefore, it is speculated that the locomotion of neutrophils does not necessarily depend on a large amount of glycogen in their cells. Whereas, in phagocytosis of the neutrophils, the neutrophils in the eel injected withthe formalin-killed cells of $E$. coli showed a marked phagocytosis after incubation for $30 \mathrm{~min}$. From those fact, it is probable that the glycogen is used as an energy source for phagocytosis rather than for their locomotion. And it is to be noted that the phagocytosis is likely to be taken place nonspecifically, from the fact that the neutrophils in the eel injected with $E$. coli responded quickly for the administration of $E$. tarda.

Thus, the neutrophils play a major role in primary response against bacterial infections.

\section{References}

CAtes, K. L., C. E. Ray, and P. G. Quie (1978): Modified boyden chamber method of measuring polymorphonuclear leukocyte chemotaxis. In Leukocyte Chemotaxis, Raven Press, New York, pp. 67-71.

KAKINUMA, K. (1976): Oxygen metabolism of phagocytes. The Cell, 12(4), 45-51.

Montgomery, R. (1957): Determination of Glycogen. Arch. Biochem. Biophys., 67, 378-386.

NaGamura, Y. and H. WaKabayashi (1983): Periodic acid-shiff reaction of neutrophils of the Eel, Anguilla japonica. Fish pathology, 17(4), 269-280.

WAGNER, R. (1947): Studies on the physiology of the white blood cell. Blood, 2, 235-243. 